Psychology of Language and Communication 2019, Vol. 23, No. 1

\title{
Sciendo
}

DOI: $10.2478 /$ plc-2019-0005

\author{
EDY VENEZIANO \\ Paris Descartes University, Paris, France
}

\section{CONVERSATIONALLY AND MONOLOGICALLY-PRODUCED NARRATIVES: A COMPLEX STORY OF HORIZONTAL DÉCALAGES}

\begin{abstract}
Theory-of- mind-related abilities present a long development characterized by both vertical and horizontal décalages. A vertical type of décalage can be seen in children's abilities to take into account, on a practical level, others' intentional and mental states and use internal state terms to talk about them before they are able to succeed, at the dominant representational level of functioning, in false belief tasks. Several horizontal décalages can also be observed. It is only after success in FB tasks that children can talk about the mental states of characters in fictional stories. Moreover, ToM-related and other inferential elements are expressed earlier and more frequently in conversationally-constructed than in monologically-produced narratives. This paper examines in particular this type of horizontal décalage by comparing the types of explanations produced by eighty 6- and 7-year-old French-speaking children during a short conversational intervention (SCI) focused on the causes of the story events to those expressed in monological narratives, about the same wordless picture story, produced immediately after or before the SCI. The results confirm that children expressed more ToMrelated and other inferential elements during the SCI than in the two monologically-produced narratives. However, the comparison between explanations produced during the SCI and in the immediately following monological narrative also reveals complex relations among understanding, knowing and expressing this knowledge. The reasons and the significance of the horizontal décalages found in the study are discussed.
\end{abstract}

Keywords: narrative development, monological narratives, conversationally-constructed narratives, horizontal décalages, theory of mind

Address for correspondence: Edy Veneziano, Université Paris Descartes, Institut de Psychologie, Laboratoire LPPS, 71, Boulevard Edouard Vaillant, 92100 Boulogne Billancourt, Ile de France, France. E-mail: edy.veneziano@parisdescartes.fr 


\section{Introduction}

Barbara Bokus is one of the authors who raised and clearly discussed a seeming paradox in research on the development of 'theory of mind' (ToM). In her original and extensive work on narratives and on children's expression of the world of consciousness involving the perspectives and the mental states of characters, both in the 'narrative line' and in the 'narrative field' (Bokus, 1996, 1998, 2004, 2013), she highlighted the time-lag that appears to exist between children's success in classical ToM tasks, such as false belief tasks (Wimmer \& Perner, 1983), and children's abilities to talk about their own or others' mental states, particularly in a narrative context (e.g., Bokus, 2013). Another - even more importantdécalage appears if we consider that young children are capable of taking into account the psychological states of their interactional partners before they can succeed at classical ToM tasks (Astington, 2001; Veneziano, 2009, 2010). Indeed, young children seem to have ToM-related understanding at the practical level when, in their everyday life, they try to attain their own goals and manage their interaction with familiar adults or peers. Different types of behaviors suggest this, including early nonverbal demands for attention and attempts to share a common referent with a partner (e.g., Tomasello, 1995), to asking differently for an object depending on whether the addressee was present or not at the time of its hiding (O'Neill, 1996), to taking into account the desires of a partner even when these are different from one's own (Repacholi \& Gopnik, 1997), or taking into account the addressee's point of view when demanding a needed object (Grosse, Moll, \& Tomasello, 2010). Young children can also show that they take into account the knowledge state of their immediate interlocutor by using language in an informative way by providing explanations, albeit primitive, for their requests and refusals (Dunn, 1991; Veneziano \& Sinclair, 1995; Veneziano, 1999, 2001), or talking about past events within a scaffolded conversation with a familiar adult who is knowledgeable about the events to be recounted (e.g., Eisenberg, 1985; Miller \& Sperry, 1988; Sachs, 1983; Veneziano \& Sinclair, 1995). Furthermore, young children can not only take into account the attentional, intentional and knowledge states of their interactional partner, but can also talk about them using words that refer to internal states. At first they refer to physical, emotional or intentional states, and progressively also to the epistemic states of knowing, thinking and believing (e.g., Bartsch \& Wellman, 1995; Baumgartner, Devescovi, \& D'Amico, 2000; Dunn, Bretherton, \& Munn, 1987; Shatz, 1994; Veneziano, 2009).

The variety and extent of these décalages indicate that theory of mind capacities are complex and diverse and cannot be reduced to children's performance in test-like situations such as the false belief paradigm (Wimmer \& Perner, 1983). Indeed, ToM-related capacities develop from early 
infancy into late school-age years (e.g., Astington, 2006; Chandler, 2001) and their different manifestations during this development can be considered examples of vertical or horizontal décalages.

\section{On vertical and horizontal décalages}

Piaget distinguished two main kinds of décalages: horizontal and vertical. Vertical décalage concerns the fact that a given cognitive operation that the child is able to execute in action, acquired for example at the sensorimotor level (such as object permanence, that is, a sort of conservation of the object in spite of its appearances and disappearances from the child's perceptual field) needs to be reconstructed at a new, higher level of functioning - the conceptual level of thought - when the child is called upon "to think in words and in notions" (Piaget 1937/1971, p. 317). With regard to ToM, knowledge can be available to the child at the sensorimotor level of 'savoir faire' ('know-how'), when children take their reference points in the immediate situation, which is often recurrent and ritualized. This 'savoir faire', needs to be reconstructed and reworked at a higher level of thinking and awareness (Karmiloff-Smith, 1992; Piaget, 1974). In contrast, horizontal décalages occur within the same level of functioning (sensorimotor, concrete or formal operations) for a given notion. In this case, a notion is well applied to a given content, but cannot immediately apply to all kinds of contents. Thus, for example, the child can understand the conservation of length, number and substance before s/he can apply the same kind of reasoning to weight or volume (e.g., Piaget \& Inhelder, 1941). Horizontal décalages are considered to show that a cognitive notion is not known from the start in a purely abstract way but is related to the objects and contents on which it bears, and thus the contents on which children operate can influence the way the notion is applied. The notion is well mastered when it is minimally influenced by the specific contents on which it applies (Piaget, 1941, p. 263.).

\section{ToM capacities: different modalities and different levels of functioning}

As mentioned above, the development of ToM capacities is a lengthy and multidimensional process (e.g., Veneziano, 2009), and it can be considered to present both vertical and horizontal décalages. A vertical décalage exists between the early behaviors - such as those mentioned above - and successful performance in false belief tasks. Early behaviors showing that, on a practical level and in conversation with their familiar partners, young children can take into account and talk about the internal states of their interactional partner, are still pervaded with sensorimotor functioning as they only occur in familiar situations where the child pursues his/her own goals. Later behaviors, instead, require a representational inferential reasoning together with the ability to distance oneself from others, and to attribute a mental state - different from one's own - to the character of the false belief story. It can be assumed that 
early behaviors (e.g., taking into account and talking about the internal states of oneself or others in everyday situations to attain one's goals) provide a basis for the development of the behaviors occurring later at a higher and completely representational level of functioning (including the attribution of a false belief to the character of the 'unknown displacement' story).

The development of ToM capacities also shows horizontal décalages. At the still dominant sensorimotor level, a longitudinal study showed, for example, that taking into account the intentional and epistemic states of a partner somewhat precedes talking about the epistemic states of oneself or others (Veneziano, 2009). At the dominantly representational level of functioning, children do not succeed in all ToM tasks at the same time. Children usually succeed in appearance/reality tasks (e.g., Flavell, et al., 1986) before false belief tasks, with a systematic priority of the 'unexpected content' task (such as the box of Smarties that contains in fact a pen: Perner, Leekam, \& Wimmer, 1987) over the 'unexpected transfer' tasks (such as the classical Maxi and the chocolate story: Wimmer \& Perner, 1983) (e.g., Veneziano, Plumet, Angeard, \& Moutier, 2012), although the difficulty of the latter task can be modulated by specific conditions of personal involvement or hints given to the children (see Melot, 1999, for an extensive discussion of these issues).

Likewise, narrative skills present both vertical and horizontal décalages. A vertical décalage is observed between behaviors occurring in the still dominant sensorimotor period and those occurring when representational functioning is dominant. Thus, one-and-a-half to two-year olds, in conversation with their familiar partners, can talk about past personal experiences or tell a short fictional story, particularly if it has already been told several times in the past. It is only later, however, when representational functioning becomes dominant, that children initiate narratives, tell them without the close support of conversational partners, and are able to enrich them with evaluative/inferential elements that contribute to narrating a coherent, causally-linked plot.

Narrative skills also show horizontal décalages. When the representational level of functioning is dominant, the expression of evaluative/inferential elements such as explanations and the attribution of mental states does not occur in all settings and kinds of stories at the same time. In fact, the structural organization and linguistic expression of personal life and fictional narratives develops through the school years up until adolescence and even adulthood (Berman, 2009; Berman \& Slobin, 1994; Hickmann, 1995). The manifestation of narrative skills varies depending on the content and on the context in which children produce their narratives. For example, narratives of personal experience, particularly if relating recurrent events, contain more evaluative elements than children's construction of fictional stories (Berman, 2004; Nelson, 1999), as do conversationally-framed narratives compared to monologically-produced ones (e.g., Berman, 2004; Bokus, 1996; Eaton, 
Collis, \& Lewis 1999; Shiro, 2003). Differences also exist depending on whether children talk about the main characters (in 'the narrative line') or characters in 'the narrative field' (e.g. Bokus, 2013).

\section{The current study}

The study presented here addresses yet another kind of horizontal décalage, that between conversationally and monologically-produced narratives. In particular, it will consider children's understanding and expression of the causes of the story events and of the mental states of the characters motivating their behavior, in a conversation focused on the explanation of the events, and their expression in a monological narrative produced before and after such a conversation. To this effect, we will analyze data gathered in a study where a short conversational intervention was implemented in between a first and a second narrative, produced monologically by the same children about the same wordless pictured story. We will consider what children seem to understand and know about the causal structure of the story, revealed by their answers to the questions asked by the experimenter during the short conversational intervention (SCI), what the same children said earlier in their previous monologically produced narrative of the same pictured story, and what they say about the same story in their subsequent monological narrative produced after the SCI. The comparison between what the children say during the SCI and their previous and subsequent monologically-produced narratives will provide new and hitherto unreported results to finely determine whether conversationally-supported narration indeed leads to the expression of a higher level of evaluative/inferential content than is the case for monologically-produced narration. The comparison with the previously produced monological narrative may confirm results obtained in earlier studies according to which conversationally-supported narratives, especially if focused on the causes of the events as is the case here, have an overall higher inferential content than monologically-produced ones. The results reported here can be considered stronger in that they involve the same children and the same story. For the comparison between what children understand and express during the SCI and in the subsequent monologically-produced narrative, two possibilities are envisaged. If the children express a higher inferential content in the SCI than in the subsequent monological narrative, this would provide even stronger evidence in favor of a horizontal décalage between the two modalities. In fact, it would show that the child can express inferential content in the conversational setting but cannot provide the same level of expression when the narrative is produced monologically, even after having just expressed it during the SCI. If, on the contrary there is no difference between the SCI and the second narrative, or an advantage to the latter, then it would mean that the horizontal décalage between conversationally-supported and monologically-produced narratives 
is not necessarily due to the modality in itself but to other factors that the SCI manages to neutralize. Thus, this comparison is a crucial test for determining whether there is indeed a difference between conversational and monological narratives due to the modality in which stories are told, and may also shed light on the complex relation between understanding, knowing and expressing what is understood.

In the results section below, we first summarize results concerning the comparison between the first and the second monologically-produced narratives. This comparison aims to check whether earlier results showing the positive effects of the SCI on the evaluative-inferential content of the monological narrative produced after the SCI are confirmed. It will also set the stage for the other two comparisons, that between the SCI and the subsequent narrative and that between the SCI and the previously produced one. We then report the results of these two comparisons that specifically address the main issues of this study.

\section{Method}

\section{Participants}

The participants were 80 French-speaking children attending first $(n=43)$ and second $(n=37)$ grades in an elementary school in Paris. The children were aged between $6 ; 1$ ( $=6$ years and one month) and 8;7 and were all reported to be typically-developing.

\section{Material}

The Stone story. To assess children's narrative skills before and after the short conversational intervention (SCI), we used the Stone story, adapted by Veneziano and Hudelot (2006) from a wordless picture story published in a collection designed for young children (Furnari, 1980). The Stone story, already used in previous research (e.g., Veneziano \& Hudelot, 2006, 2009; Veneziano, 2010, 2016; Veneziano et al., forthcoming) consists of five wordless pictures (see Appendix A) and is meant to represent a story of a misunderstanding between two characters.

The first picture sets the stage, showing two boys (referred to hereafter as P1 and P2) waving hello to each other from a distance (the 'greeting'). The second and third pictures represent the 'complicating event': the accidental stumbling of P1 on a stone, leading to P1 'pushing' P2 - the source of the misunderstanding by P2 of P1's behavior - followed by P2 'pushing back' P1. The fourth picture represents the 'resolution attempt', showing P1 crying and pointing towards the stone. The fifth picture represents 'the resolution', showing $\mathrm{P} 2$ helping P1 to get up. 


\section{Procedure}

Children were individually interviewed in a quiet room. All interviews were audio and video recorded and were carried out by the same experimenter. First, children looked at the five wordless pictures of the Stone story, presented sequentially in the right order. Once the child was ready to tell the story, the pictures were removed ${ }^{1}$ and the child narrated his/her story. After this first monologically- and autonomously produced narrative (hereafter referred to as FMN for first monological narrative), the experimenter introduced the Short Conversational Intervention (SCI). While the pictures were again placed in front of the child, the experimenter asked the child questions meant to focus his/ her attention on the causes of the four main events of the story. "How come" or "Why": 1. P1 pushes P2 ('the first push'); 2. P2 pushes P1 ('the second push'); 3. P1 shows the stone ('pointing towards the stone'); and 4. P2 helps P1 to get up ('the reconciliation'). After the SCI, the children were asked to tell the story once again - the second monological narrative - (hereafter referred to as $\mathrm{SMN}$ ). As was the case for the first narrative, the children told the story after the pictures had been removed.

\section{Data analysis}

All the children's narratives were transcribed verbatim. For the purposes of this study, we considered the expression of the following inferential aspects, that is, those aspects that require interpretations going beyond what is represented in the pictures: the explanation of events and the attribution of internal states to the characters, including the more complex states of false belief and its rectification.

The explanation of events. For the comparison between the first monological narrative (FMN) and the second (SMN), we identified all the explanations provided by the children in each narrative and coded them as referring to physical (for example, il trébuche à cause de la pierre 'he stumbles because of the stone'), socio-conventional (for example, comme il l'avait poussé, il l'a poussé aussi 'as he pushed him, he pushed him too'), or internal state explanations (for example, il pleure parce que il a eu mal 'he cries because he hurt himself').

For the comparison between the kinds of explanations provided during the SCI and each of the two monological narratives (FMN and SMN), we coded children's responses to the four causal questions asked during the SCI. These were categorized as appropriate to the story of a misunderstanding (misunderstanding-relevant explanations, referred hereafter as MRE), as providing explanations of the events but not contributing to the story of a misunderstanding (called 'other explanations' and referred to hereafter as

\footnotetext{
1 The reason for this was to minimize children's attention on the details of the pictures and to optimize the chances of having the children talk about non perceptible, inferential aspects of the story.

${ }^{2}$ Both P1 and P2 were named in the same way as the children had done in their first narrative.
} 
$\mathrm{OE}$ ), and as no explanatory responses (NoE). For the purposes of this study, the same categorization was also applied to the explanation (or lack of explanation) of the events mentioned in the FMN and in the SMN. For each question, the following were considered misunderstanding-relevant explanations (MRE):

1) For the first push (P1 pushes P2): the physical cause and/or tmention of the non-intentionality of $\mathrm{P} 1$. For example, il a poussé son copain sans faire exprès 'he pushed his pal without doing it on purpose';

2) For the push back (P2 pushes P1 back): the belief of P2 that P1 had intentionally pushed P2. For example, comme il croyait qu'il l'avait poussé exprès, il l'a poussé lui aussi 'as he believed he had pushed him on purpose, he pushed him too';

3) For P1 showing P2 the stone: the explanation by P1 of what caused his initial push (rectifying the belief of $\mathrm{P} 2$ ). For example, pour dire que c'était pas sa faute, c'était à cause de la pierre qu'il l'avait poussé 'to say that it wasn't his fault, it was because of the stone that he pushed him';

4) For P2 helping P1 to get up: the fact that P2 understands what had happened earlier to $\mathrm{P} 1$. For example, il l'aide parce qu'il a compris pourquoi il l'avait poussé 'he helps him because he understood why he pushed him'.

The attribution of internal states. For the comparison between the two monologically-produced narratives (FMN and SMN), all the internal states that the children attributed to the characters were noted: physical (e.g., il a mal 'he is in pain'), emotional (e.g., il est mécontent 'he is unhappy'), intentional (e.g., il ne voulait pas le pousser 'he didn't want to push him') and epistemic states. The latter included believing, knowing, thinking and understanding, the attribution of the false belief (for example, il l'a poussé à cause de la pierre et son copain il y a cru qu'il l'avait poussé exprès 'he pushed him because of the stone and his pal believed he had done it on purpose') and of its rectification (for example, il dit à l'autre que c'est à cause du caillou qu'il a trébuché et qu'il l'a poussé 'and he says to the other one that it is because of the pebble that he stumbled and that he pushed him') (for more details on the coding system used for the comparison between FMN and SMN see, for example, Veneziano, 2016 and Veneziano et al., forthcoming). 


\section{Results}

\section{Comparison between the first and the second monological narratives (FMN vs. SMN)}

The second monological narratives (SMN) produced after the SCI contained more explanations $^{3}(t=7.225, p<.001)$, more internal state attributions $(t=4.88, p<.001)$, more epistemic states $(t=2.983, p<.001)$, as well as more attributions of false belief to $\mathrm{P} 2$ and of the rectification of the false belief by $\mathrm{P} 1(t=5.691, p<.001)$, which are both more complex epistemic states than the attribution of simply knowing, thinking or believing.

As already mentioned, these results confirm those obtained in earlier studies that used the SCI procedure. They show the effect of the SCI on the SMN, this being particularly evident in those studies where the control group (who did not participate in the SCI) didn't obtain such an effect (Veneziano et al., 2009; Veneziano, 2016; Veneziano et al., forthcoming).

From these results, however, we do not know what the relation is between children's responses in the SCI and what they later express in their SMN, nor between the FMN and what children are capable of expressing during the SCI. These comparisons are reported in the next two sections. We first present the comparison between what children expressed during the SCI and in the subsequent $\mathrm{SMN}$, and then the comparison between what children expressed during the SCI and what they had said previously in the FMN

\section{Comparison between the explanations expressed during the SCI and those expressed in the subsequent monological narrative (SMN)}

As described in the data analysis section above, children's responses to the four causal questions asked during the SCI were categorized as appropriate to the story of a misunderstanding (MRE), as providing explanations of the events but not contributing to the story of a misunderstanding (OE), or as no explanatory response (NoE). The same categorization was applied to the corresponding events mentioned in the monologically-produced narratives. During the SCI, $31 \%$ of the children (25 out of 80 ) were able to explain all four events with MREs. However, out of the 25 , only $52 \%$ of them (13 children) told a monological narrative (SMN) in which all four events were explained in a misunderstanding relevant way. The other twelve children (48\%), for at least one of the events, provided either another explanation $(\mathrm{OE})$ or no explanation at all $(\mathrm{NoE})$.

Table 1 presents the comparison between the explanations (or lack thereof) provided during the SCI and those provided in the SMN, for each of the four events discussed. It shows the percentage of children who: a)

\footnotetext{
${ }^{3}$ All values correspond to t-values for paired t-tests (with $d f=79$ ) and the probabilities are given for one-tailed tests given that the hypotheses are directional: the 2nd narrative contains more inferential components than the $1^{\text {st }}$ narrative.
} 
maintained the same type of explanation (including the lack of explanation) in the SCI and in the SMN; b) produced a lower type of explanation in the SMN compared to what they had said during the SCI (from MRE in the SCI, to OE or NoE in the SMN; or, from OE in the SCI to NoE in the $\mathrm{SMN}$ ); or c) produced a higher type of explanation in the SMN than during the $\mathrm{SCI}$ (from NoE in the SCI, to OE or MRE in SMN; or, from OE in the SCI to MRE in SMN).

Table 1. Comparison between the explanations (including NoE) provided during the SCI and in the SMN: Proportion of children producing: a) the same type of explanation in the SCI and in the SMN; b) a lower type of explanation in the SMN; c) a higher type of explanation in the SMN, for each of the four events.

$\%$ of children producing in the SMN explanations of

\begin{tabular}{lccc}
\cline { 2 - 4 } Events & a) same type & b) lower type & c) higher type \\
\hline 1. First push & $61 \%$ & $25 \%$ & $14 \%$ \\
2. Push back & $35 \%$ & $45 \%$ & $20 \%$ \\
3. Showing the stone & $39 \%$ & $45 \%$ & $16 \%$ \\
4. Helping to get up & $28 \%$ & $56 \%$ & $16 \%$ \\
\hline
\end{tabular}

Overall, about a third of the children maintained the same level of explanation in the SMN as that expressed during the SCI, a percentage that is twice as high for the first push. Some even produced a higher type of explanation in the SMN than during the SCI. However, with the exception of the first push, the highest proportion of children produced a lower type of explanation in the SMN than in the SCI. It is interesting to note here that while the first push requires a physical type of explanation (P1 pushes P2 because of the stone), the other three events, in order to tell a story of a misunderstanding, require mental explanations of the epistemic type. For these events, what children seem to understand and are able to express during the SCI is higher than what they express in the SMN, thus showing for these events a larger décalage in favor of the SCI than for the first event, for which a physical cause is sufficient.

To better grasp the nature and the extent of this décalage, we will focus on those cases where the children expressed misunderstanding-relevant explanations (MREs) during the SCI and examine what kind of explanation they produced in the SMN. In the SMN, do children provide explanations of the same level (MREs), or is the same event explained with other explanations (OEs) or is not explained at all (NoEs)? Table 2 presents the number of children who, for each event, had expressed MREs during the SCI and the proportion of these children who, in the SMN, explained the corresponding event with either an explanation of the same type (MRE), another explanation (OE), or did not explain the event at all $(\mathrm{NoE})$ : 
Table 2. Number of children who peovide MREs during the SCI and proportion of these children producing in the SMN: a) MRE; b) OE c) NoE, for each of the four events..

\begin{tabular}{lcccc}
\hline & $\begin{array}{c}\text { Number } \\
\text { of children } \\
\text { producing } \\
\text { MRE in } \\
\text { the SCI }\end{array}$ & & a) of these children producing in the SMN: \\
\cline { 3 - 5 } Events & 64 & $72 \%$ & $3 \%$ & (2) OE \\
\hline 1. First push & 44 & $45 \%$ & $7 \%$ & c) NoEe \\
2. Push back & 44 & $64 \%$ & $0 \%$ & $48 \%$ \\
3. Showing the stone & 43 & $33 \%$ & $9 \%$ & $58 \%$ \\
4. Helping to get up & & & & \\
\hline
\end{tabular}

For all the events, and in particular for the first and the third one, many of the children who provided MREs during the SCI also provided this same type of explanation in the SMN. However, a good proportion of the children either did not produce any explanation of the event or, in a few cases, provided a non-MR explanation (OE). The example below illustrates the first profile: the child provided a MRE for event 2 (the push back) in the SCI, but did not explain that same event in the SMN (NoE):

REI 6;7

During the SCI, for event 2, the experimenter says:

Did you understand why the boy on the left pushes the other one back?

The child says:

il croyait qu'en fait c'était pour de vrai qu'il le poussait

'he believed that in fact he pushed him for real'

In the SMN produced after the SCI, the child only says:

après l'autre il pousse celui de droite 'afterwards he pushes the one on the right'.

To summarize, the results obtained in this comparison reveal a rather complex picture. A sizeable proportion of children produced a lower level of explanation in the SMN than in the SCI. These children confirm the existence of a horizontal décalage in favor of the conversationally-produced narration, a décalage that is particularly interesting as it exists in spite of the fact that the children had just expressed the MRE explanations during the SCI. But there is also a good proportion of children who maintain in the SMN the misunderstanding-related explanations provided during the SCI, and some children even produce a higher level of explanation in the SMN than in the SCI. These results go against the décalage in favor of the conversationally-produced narratives and indicate that the fact of having expressed or thought about the causes of the events during the SCI helps children to overcome the difficulties inherent in the monological type of 
storytelling. In oter words, children's participation in the SCI reduces the horizontal décalage between conversationally and monologically produced narratives. The comparison between the SCI and the FMN will provide further data on this point.

\section{Comparison between explanations produced during the SCI and those expressed previously in the first monological narrative (FMN)}

The décalage between the SCI and the FMN should be more clear-cut than that observed between the SCI and the SMN above. Indeed, as discussed above, earlier studies have shown that children produce evaluative/inferential components earlier in a conversational than in a monological setting; moreover, all the studies conducted with the SCI procedure have shown a significant increase in these elements between the narrative produced before (FMN) and that produced after $(\mathrm{SMN})$ the $\mathrm{SCI}$, a result again confirmed in the present study (see the first section of the results above).

Table 3 presents data similar to those presented in Table 2 for the comparison between the SCI and the SMN. It shows, for each event, the number of children who provided misunderstanding-relevant explanations (MREs) during the SCI and the proportion of these children who, in the FMN, explained the corresponding event with either an explanation of the same type (MRE), another explanation (OE), or did not explain the event at all (NoE):

Table 3. Number of children who provide MREs during the SCI and proportion of these children producing in the FMN: a) MRE; b) OE c) NoE, for each of the four events..

\begin{tabular}{lcccc}
\hline & $\begin{array}{c}\text { Number } \\
\text { of children } \\
\text { producing } \\
\text { MRE in } \\
\text { Events }\end{array}$ & & \% of these children producing in the FMN: \\
\cline { 3 - 5 } & 64 & $48 \%$ & $3 \%$ & $48 \%$ \\
\hline 1. First push & 44 & $25 \%$ & $20 \%$ & $55 \%$ \\
2. Push back & 44 & $36 \%$ & $0 \%$ & $64 \%$ \\
3. Showing the stone & 43 & $58 \%$ & $9 \%$ & $33 \%$ \\
4. Helping to get up & & & & c) \\
\hline
\end{tabular}

With the exception of the first and the fourth events, for which about half of the children who expressed MR explanations during the SCI had already produced them in the FMN, for the other two events, which are at the core of the misunderstanding, the majority of the children who provided an MRE during the SCI had either not produced any explanation or had provided OEs in the FMN. As expected, these results show the existence of a larger décalage between the evaluative/inferential content children produce in the FMN and the one they provide during the SCI, and this even for the first push that 
requires a physical explanation. Thus, children who cannot provide MRE in their FMN are nevertheless able to do so when conversing with the experimenter about the causes of the events.

\section{Discussion}

The results of this study have clearly revealed two horizontal décalages in children's narrative skills: The décalage between the types of explanations provided in the FMN and those expressed within the SCI, and the décalage between the types of explanations produced during the SCI and those expressed in the SMN.

The décalage FMN-SCI is clear-cut in favor of the SCI and it was somewhat expected. It shows that children can tell more evaluative narratives in a conversational than in a monological setting. It confirms results obtained in earlier studies showing the facilitating role of conversations for the expression of evaluative/inferential components, such as explanations and references to the characters' internal states (e.g., Berman, 2004; Eaton, Collis, \& Lewis, 1999; Shiro, 2003). Its presence also provides a strong indication that the improvements found in the SMNs produced after the SCI, found here and in previous studies (Veneziano, 2016, 2017; Veneziano, Albert, \& Martin, 2009; Veneziano \& Hudelot, 2009; Veneziano \& Plumet, 2019), are closely related to what children express during the SCI. Indeed, the improvements in the SMNs occur after the children expressed MREs during the SCI, MREs that for the most part were not expressed earlier in the FMN, and many of which were maintained in the SMN.

The décalage SCI-SMN is more complex and varied. On the one hand, the result concerning the children who express lower types of explanations in the SMN after having expressed MREs during the SCI constitutes an even stronger confirmation that the conversational setting facilitates the expression of richer and more evaluative narratives. Indeed, it shows that a good number of children who have manifested an understanding of the story as a story of a misunderstanding, and have verbally expressed it in the conversational setting, cannot integrate and express that understanding in their SMN even though the latter was produced immediately afterwards. This means that, for some children, the understanding of the mental world of the characters and of the overall story, and even its verbal expression, cannot overcome the seeming difficulties of narrating a fictional story in a monological way. On the other hand, results also show that many children are able to maintain in the SMN the higher level of understanding and expression manifested during the SCI. They even show a décalage in favor of the SMNs: children who did not provide MREs during the SCI (where they provided OEs or NoEs) were able to produce MREs in the SMN. This result, though concerning a limited number of children, is a counterexample to the facilitating role of 
the conversational relative to the monological setting. Together with the results showing that children can maintain the level of expression attained during the SCI, these results suggest that the décalage in favor of the conversational modality may, under certain circumstances, be neutralized. In our case, this neutralizing role may be played by the SCI itself. Indeed, the higher performance observed in the SMN occurs after children participated in the SCI in which they were led to express, or anyway to think about, the causes of the events in a conversational setting. In some cases, the questions asked may have had a delayed effect on these children's understanding of the story as a story of a misunderstanding, and on its expression, that surfaces only later in the SMN. This result is similar to the one observed in studies where children were tested one week later to check whether the improvements obtained immediately after the SCI were retained after a temporal delay. The improvements were retained for the most part. Moreover, one week later, some children managed to provide inferential content they had not produced in the SMN told immediately after the SCI (Veneziano et al., 2009; Veneziano et al., forthcoming).

Taken together, the results revealed by the SCI-SMN comparison indicate that the relation between thinking, knowing and expressing one's knowledge is rather complex. On the one hand, they show that, for some children, the verbal expression of the understanding of the story attained in the SCI is not sufficient to overcome the difficulties of producing the narrative monologically. On the other hand, they show that the décalage can be eliminated when children express the higher level of understanding during the SCI. They also show that it is even unnecessary to verbally express MREs in the SCI to express them later in the SMN, the expression of the mental aspects of the story occurring then directly during the seemingly more difficult setting, thus tilting the décalage in favor of the monological narrative. Intervention studies, as well as studies showing the facilitating role of certain conditions and procedures, need to take into account this complexity in the relation between understanding, knowing and expressing, as well as the individual variation that seems to be present in the way this relation is realized.

\section{Reasons and significance of the horizontal décalage between conversationally and monologically-produced narratives}

As our results show, the expression of the story in terms of the intentions and beliefs of the characters (revealing theory-of-mind-related knowledge) does not occur across the board. Its implementation depends on variables such as the nature of the task (conversational vs. monological), the conditions in which it applies (e.g., FMN vs. SMN), or the contents to be expressed (e.g., physical vs. mental explanations). In this study, we found that children were able to express a story of a misunderstanding during the SCI at a time when only a few of them were already capable of doing so in the FMN. 
Moreover, that not all the children who provided MREs during the SCI did so in the SMN, although they had just expressed those components in the SCI.

The reasons for these horizontal décalages can be found in some facilitating features of the conversational procedure. For example, in conversation, the story is segmented into its components. By focusing their attention on the events one at the time, the children can better explore the pictures, make links between pictured and inferred elements, and so ease the cognitive load of treating the overall material at once. This supposedly better apprehension of the pictured story occurs together with a key element, the questions about the causes of the events and behaviors of the characters. Children who may not have thought about this aspect have the opportunity to consider it and possibly discover the mental motivations for the characters' behaviors. At the same time, through the repeated manifestation of the experimenter's interest about the causes of the events, the causal structure of the story may become salient component of a narrative considered interesting to tell to the interlocutor (e.g., Hausendorf \& Quasthoff, 1992).

In contrast, monological narratives require simultaneous autonomous thinking about the different components of the story. The sequence of pictures needs to be interpreted as a unique story having thematic coherence, and children have to think about and understand the causal structure of the overall story by themselves. Moreover, they have to find the linguistic means, such as cohesion devices, to communicate the story plot (e.g., Hickmann, 1995). Children who have not yet well mastered the various competencies required by the task may have difficulties in bringing all of them to bear simultaneously on their storytelling, particularly if the story requires talking about ToM-related aspects such as the characters' intentions, beliefs and their different viewpoints on an event (e.g., Aksu-Koç \& Tekdemir, 2004; Veneziano, 2016; Veneziano \& Hudelot, 2009). These differences in the cognitive and linguistic resources required by the conversational and the monological settings may indeed result in monologically-produced narratives containing fewer ToM-related elements than narratives that are produced conversationally. However, as mentioned earlier, monological narratives can catch up on conversationally-produced ones when higher level contents are worked upon in shared conversation, even if the children do not express their understanding during the conversation itself.

Do these horizontal décalages mean that children's 'real' competences are those manifested in the most favorable conditions and with the most favorable contents? And that children's 'real' narrative competences are best captured in 'natural' conditions when children narrate their own personal experiences, tell stories that interest them, are motivated to communicate them, or when their storytelling is scaffolded by the conversational turns of an adult? If the aim is to capture the early manifestations of children's capacities in telling stories containing evaluative/inferential elements, it is certainly important to 
observe children telling narratives about the most favorable contents and in the most facilitating conditions. However, from a developmental viewpoint, all the contents and conditions are important to consider, as children's performance in each one of them reveals where $\mathrm{s} / \mathrm{he}$ stands on this development, how robust and well-mastered the skill is, up to fully expressing itself independently of the difficulties provided by the contents and/or the conditions in which it is carried out. It is at this point that an individual can be considered to have attained 'expert narrative skills' (see Nelson \& Khan (2019) for a detailed description of the development leading to the attainment of this expertise).

\section{References}

Aksu-Koç, A., \& Tekdemir, G. (2004). Interplay between narrativity and mindreading: A comparison between Turkish and English. In S. Strömqvist \& L. Verhoeven (Eds.), Relating events in narrative: Typological and contextual perspective (pp. 307-327). Mahwah, NJ: Erlbaum.

Astington, J. W. (2001). The future of theory-of-mind research: Understanding motivational states, the role of language, and real-world consequences. Child Development, 72, 685-687.

Astington, J. W. (2006). The developmental interdependence of theory of mind and language. In S. C. Levinson, \& N. J. Enfield (Eds.), The roots of human sociality: Culture, cognition, and human interaction (pp. 179-206). Oxford: Berg.

Bartsch, K., \& Wellman, H.M. (1995). Children's talk about the mind. New York, NY: Oxford University Press.

Baumgartner, E., Devescovi, A., \& D'Amico, S. (2000). Il lessico psicologico dei bambini. Roma: Carocci Editore.

Berman, R. A. (2004). The role of context in developing narrative abilities. In S. Strömqvist \& L. Verhoeven (Eds.), Relating events in narrative: Typological and contextual perspectives (pp. 261-280). Mahwah, NJ: Lawrence Erlbaum.

Berman, R. A. (2009). Trends in research on narrative development. In S. FosterCohen (Ed.), Language acquisition (pp. 294-318). Basingstoke: PalgraveMacmillan.

Berman, R. A., \& Slobin, D. I. (1994). Relating events in narrative: A crosslinguistic developmental study. Hillsdale, NJ: Erlbaum.

Bokus, B. (1996). Narrative space structuring at the preschool age: Findings on monologic and dialogic discourse. In C. E. Johnson \& J. H. V. Gilbert (Eds.), Children's language, Vol. 9 (pp. 197-207). Mahwah, NJ: Erlbaum.

Bokus, B. (1998). Action and its representation in the minds of story characters: Findings from children's discourse. Psychology of Language and Communication, 2, 63-77. 
Bokus, B. (2004). Inter-mind phenomena in child narrative discourse. Pragmatics, 14, 391-408.

Bokus, B. (2013). Mind-reading in children's narration: Mental states ascribed to narrative line and narrative field subjects. In G. Shugar Wales, B. Bokus \& J. Smogorzewska (Eds.), From reference situation to narrative text, vol. 21 (pp. 77-111). Piaseczno, Poland: Studio Lexem. ISBN 9788393625857.

Chandler, M. (2001). Perspective taking in the aftermath of theory-theory and the collapse of the social role-taking literature. In A. Tryphon \& J. Vonèche (Eds.), Working with Piaget: In memoriam-Bärbel Inhelder (pp. 39-63). Hove, East Sussex: Psychology Press.

Dunn, J. (1991). Understanding others: evidence from naturalistic studies of children. In A. Whiten (Ed.), Natural theories of mind (pp. 51-61) Oxford, UK: Blackwell.

Dunn, J., Bretherton, I., \& Munn, P. (1987). Conversation about feeling states between mothers and their young children. Developmental Psychology, 23, $132-139$.

Eaton, J. H., Collis, G. N., \& Lewis, V. A. (1999). Evaluative explanations in children's narratives of a video sequence without dialogue. Journal of Child Language, 26, 699-720.

Eisenberg, A. R (1985). Learning to describe past experiences in conversation. Discourse Processes, 8, 177-204.

Flavell, J. H., Green, F. L., \& Flavell, E. R. (1986). Development of knowledge about the appearance-reality distinction. Monographs of the Society for Research on Child Development, 51(1, Serial No. 212).

Furnari, E. (1980). Esconde-Esconde para Crianças de 3 a 5 años. Atica: Brésil.

Grosse, G., Moll, H., \& Tomasello, M. (2010). 21-month-olds understand the cooperative logic of requests. Journal of Pragmatics, 42, 3377-3383.

Hausendorf, H., \& Quasthoff, U.M. (1992). Children's storytelling in adult-child interaction: three dimensions in narrative development. Journal of Narrative and Life History, 2, 293-306.

Hickmann, M. (1995). Discourse organization and reference. In P. Fletcher \& B. MacWhinney (Eds.), Handbook of Child Language (pp. 194-218). Cambridge, MA: Basil Blackwell.

Karmiloff-Smith, A. (1992). Beyond Modularity: A developmental perspective on cognitive science. Cambridge, MA: MIT Press.

Melot, A. M. (1999). Développement cognitif et métacognitif : panorama d'un nouveau courant. Enfance, 3, 205-214.

Miller, P. J., \& Sperry, L. L. (1988). Early talk about the past: The origins of conversational stories of personal experience. Journal of Child Language, $15,293-315$.

Nelson, K. (1999). Event representations, narrative development and internal working models. Attachment and Human Development, 1, 239-252. 
Nelson, K., \& Khan, K. (2019). New frontiers in facilitating narrative skills in children and adolescents: A dynamic systems account incorporating eight narrative developmental stages. In E. Veneziano \& A. Nicolopoulou (Eds), Narratives, literacy and other skills: Studies in intervention (pp. 173-200). Amsterdam/Philadelphia: John Benjamins.

O'Neill, D. K. (1996). Two-year-old children's sensitivity to a parent's knowledge state when making requests. Child Development, 67, 659-677.

Perner, J., Leekam, S. R., \& Wimmer, H. (1987). Three-year olds' difficulty with false belief: The case for a conceptual deficit. British Journal of Developmental Psychology, 5, 125-137.

Piaget (1937/1971). La construction du réel chez l'enfant. Neuchâtel; Paris: Delachaux et Niestlé.

Piaget, J. (1941). Le mécanisme du développement mental et les lois du groupement des opérations : esquisse d'une théorie opératoire de l'intelligence. Archives de Psychologie, 28, 215-285.

Piaget, J. (1974). La prise de conscience. Paris: PUF.

Piaget, J., \& Inhelder, B. (1941). Le développement des quantités chez l'enfant : conservation et atomisme. Neuchâtel; Paris: Delachaux et Niestlé.

Repacholi B. M., \& Gopnik A. (1997). Early reasoning about desires: evidence from 14- and 18-month-olds. Developmental Psychology, 33, 12-21.

Sachs, J. (1983). Talking about the there and then: the emergence of displaced reference in parent-child discourse. In K. E. Nelson (Ed.), Children's language. Vol. 4. Hillsdale, NJ: Erlbaum.

Shatz, M. (1994). A toddler's life: Becoming a person. New York, NY: Oxford University Press.

Shiro, M. (2003). Genre and evaluation in narrative development. Journal of Child Language, 30, 165-195.

Tomasello, M. (1995). Joint attention as social cognition. In C. Moore \& P. J. Dunham (Eds.), Joint attention: Its origins and role in development (pp. 103-130). Hillsdale, NJ: Erlbaum.

Veneziano, E. (1999). L'acquisition de connaissances pragmatiques: apprendre à expliquer. Revue Parole, 9/10, 1-28

Veneziano, E. (2001). Interactional processes in the origins of the explaining capacity. In K. Nelson, A. Aksu-Koc, and C. Johnson (Eds.), Children's language: Developing narrative and discourse competence (pp. 113-141). Mahwah, N.J.: L. Erlbaum.

Veneziano, E. (2009). Language and internal states: A long developmental history at different levels of functioning. RIPLA Rivista di Psicolinguistica applicata JJournal of Applied Psycholinguistics, IX, 9-27.

Veneziano, E. (2010). Peut-on aider l'enfant à mieux raconter? Les effets de différentes méthodes d'intervention. In H. Makdissi, A. Boisclair \& P. Sirois (Eds.), La littératie au préscolaire: une fenêtre ouverte sur la scolarisation (pp. 107-144). Québec: Presses Universitaires du Quebec. 
Veneziano, E. (2016). The development of narrative discourse in French by 5 to 10 year old children: Some insights from a conversational interaction method. In J. Perera, M. Aparici, E. Rosado, \& N. Salas (Eds.), Written and spoken language development across the lifespan: Essays in honour of Liliana Tolchinsky (pp. 141-160). New York, NY: Springer Verlag.

Veneziano, E. (2017). Talking about the nonliteral: Internal states and explanations in child-constructed narratives. Psychology of Language and Communication, 21(1), 134-151. DOI: 10.1515/plc-2017-0007

Veneziano, E., Albert, L., \& Martin, S. (2009). Learning to tell a story of false belief: A study of French-speaking children. In J. Guo, E. Lieven, N. Budwig, S. Ervin-Tripp, K Nakamura, \& S. Özçaliskan (Eds), Crosslinguistic approaches to the psychology of language: Research in the tradition of Dan Isaac Slobin (pp. 277-289). New York, NY: Psychology Press.

Veneziano, E., \& Hudelot, C. (2006). Etats internes, fausse croyance et explications dans les récits: effets de l'étayage chez les enfants de 4 à 12 ans. Langage et l'Homme, 41(2), 119-140.

Veneziano, E., \& Hudelot, C. (2009). Explaining events in narratives: the impact of scaffolding in 4 to 12 year-old children. Psychology of Language and Communication, 13(1), 3-20.

Veneziano, E., Hudelot, C., LeNormand, M. T., Plumet, M. H., \& Elie, J. (forthcoming). Improving narrative skills in 5- to 8-year-old Frenchspeaking children: Immediate and delayed effects of a short conversational intervention.

Veneziano, E., \& Plumet, M. H. (2019). Promoting narratives through a short conversational intervention in typically developing and high-functioning children with ASD. In E. Veneziano \& A. Nicolopoulou (Eds), Narratives, literacy and other skills: Studies in intervention (pp.285-312). Amsterdam/ Philadelphia: John Benjamins.

Veneziano, E., Plumet, M. H., Angeard, N., \& Moutier, S. (2012). Attribution of false belief in French children: Décalages between tasks and cultural differences. 42nd Annual Meeting of the Jean Piaget Society, Toronto, Canada.

Veneziano, E., \& Sinclair, H. (1995). Functional changes in early child language: The appearance of references to the past and of explanations. Journal of Child Language, 22, 557-581.

Wimmer, H., \& Perner, J. (1983). Beliefs about beliefs: Representation and constraining function of wrong beliefs in young children's understanding of deception. Cognition, 13, 103-128 


\section{Appendix A}

\section{The Stone Story}
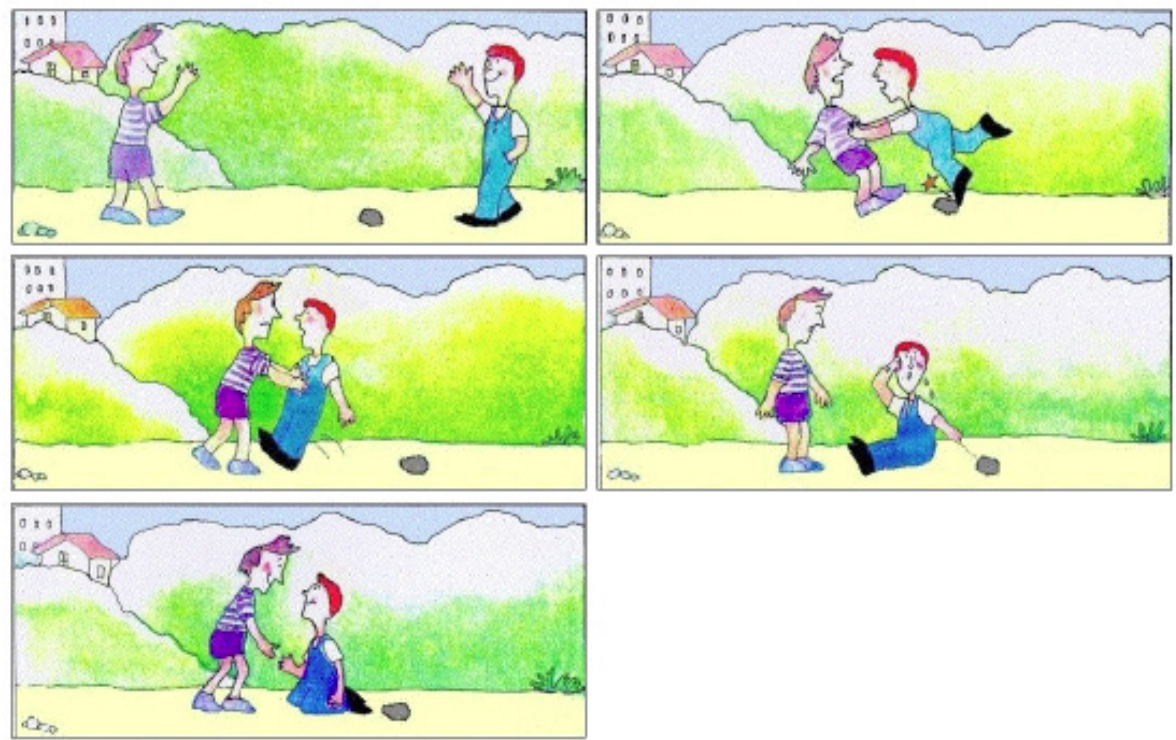